\title{
Effect of administration of allopurinol on postoperative outcomes in patients undergoing intracardiac repair of tetralogy of Fallot
}

Sachin Talwar, MCh, Murugan Sathiya Selvam, MCh, Neeti Makhija, MD, Ramakrishnan Lakshmy, MD, Shiv Kumar Choudhary, MCh,, Vishnubhatla Sreenivas, MD, and Balram Airan, MCh

\section{ABSTRACT}

Objective: To determine effects of allopurinol administration on outcomes following intracardiac repair of tetralogy of Fallot (TOF).

Materials and Methods: Fifty patients undergoing TOF repair were randomized to 2 groups of 25 each: the allopurinol group $(n=25)$ and the placebo group $(\mathrm{n}=25)$. Postoperatively, inotropic score, rhythm, duration of mechanical ventilation, cardiac output, intensive care unit (ICU) stay, and hospital stay were assessed. Plasma troponin-I, superoxide dismutase (SOD), interleukin (IL) $1-\beta$, IL-6, and malondialdehyde were measured serially.

Results: Inotropic score was lower in the allopurinol compared with placebo group $(11.04 \pm 5.70$ vs $17.50 \pm 7.83 ; P=.02)$. Duration of ICU and hospital stay was lower in the allopurinol group. Plasma levels of SOD preoperative were $(2.87 \pm 1.21 \mathrm{U} / \mathrm{mL}$ vs $4.5 \pm 2.08 \mathrm{U} / \mathrm{mL} ; P=.012)$, immediately following release of crossclamp $(2.32 \pm 0.98 \mathrm{U} / \mathrm{mL}$ vs $5.32 \pm 2.81 \mathrm{U} / \mathrm{mL} ; P<.001)$, and after termination of CPB $(2.18 \pm 1.0 .78 \mathrm{U} / \mathrm{mL}$ vs $3.44 \pm 1.99 \mathrm{U} / \mathrm{mL} ; P=.003)$ between the placebo versus allopurinol group, respectively. Postoperative levels of IL1- $\beta$ and IL-6 were lower in the allopurinol group. Malondialdehyde levels following CPB were lower in the allopurinol group $(11.80 \pm 2.94 \mathrm{pg} / \mathrm{mL}$ in the placebo vs $9.16 \pm 3.02 \mathrm{~g} / \mathrm{mL}$ in the allopurinol group; $P<.001)$.

Conclusions: Allopurinol administration in patients undergoing intracardiac repair of TOF is associated with reduced inotropic scores, duration of mechanical ventilation, ICU stay, and hospital stay and favorable biochemical markers of inflammation. Further studies in multiple setups are needed before recommending it as a routine practice. (J Thorac Cardiovasc Surg 2018;155:335-43)

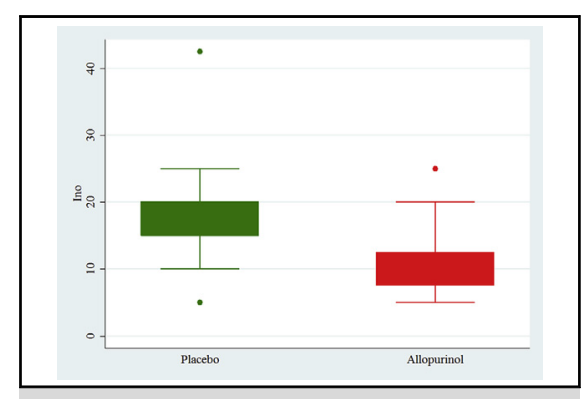

Comparison of inotropic (Ino) scores $\left(\mathrm{L} / \mathrm{min} / \mathrm{m}^{2}\right)$ between the allopurinol and placebo groups.

\section{Central Message}

Administration of allopurinol in patients undergoing tetralogy of Fallot repair is associated with lower inotropic scores, less mechanical ventilation, shorter intensive care unit and hospital stays, and favorable biochemical markers of inflammation.

\section{Perspective}

Fifty patients undergoing TOF repair were randomized to 2 groups of 25 each: the allopurinol group, in which patients were administered allopurinol, and the placebo group. Allopurinol administration was associated with reduced inotropic scores, duration of mechanical ventilation, intensive care unit and hospital stay, and favorable biochemical markers of inflammation.

See Editorial Commentary page 344
From the Cardiothoracic Center and Department of Biostatistics, All India Institute of Medical Sciences, New Delhi, India.

Supported by a research grant (No: A-307/14) of \$500,000 (\$8000) from the Research Section of All India Institute of Medical Sciences, New Delhi, India.

Read at the 96th Annual Meeting of The American Association for Thoracic Surgery, Baltimore, Maryland, May 14-18, 2016.

Received for publication May 25, 2016; revisions received July 15, 2017; accepted for publication Aug 7, 2017.

Address for reprints: Sachin Talwar, MCh, Department of Cardiothoracic and Vascular Surgery, All India Institute of Medical Sciences, New Delhi 110029, India (E-mail: sachintalwar@hotmail.com).

$0022-5223 / \$ 36.00$

Copyright (c) 2017 by The American Association for Thoracic Surgery https://doi.org/10.1016/j.jtcvs.2017.08.115
Cardiopulmonary bypass (CPB) is known to stimulate both the systemic and pulmonary inflammatory responses that may delay postoperative recovery in children undergoing heart surgery. ${ }^{1,2}$ Cyanosis and chronic hypoxia are the

Scanning this QR code will take you to the article title page. To view the AATS 2016 Webcast, see the URL next to the webcast thumbnail.

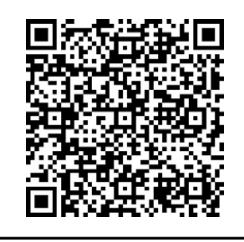




$$
\begin{aligned}
& \text { Abbreviations and Acronyms } \\
& \text { AOXC }=\text { aortic crossclamp } \\
& \text { CPB }=\text { cardiopulmonary bypass } \\
& \text { ICU }=\text { intensive care unit } \\
& \text { IL }=\text { interleukin } \\
& \text { LCOS }=\text { low cardiac output syndrome } \\
& \text { MDA }=\text { malondialdehyde } \\
& \text { ROS }=\text { reactive oxygen species } \\
& \text { SOD }=\text { superoxide dismutase } \\
& \text { TOF }=\text { tetralogy of Fallot } \\
& \text { XO }=\text { xathine oxidase }
\end{aligned}
$$

most common preoperative physiologic stressors in pediatric cardiac patients as well as important causes of adverse outcomes. ${ }^{1,3}$ In comparison to the acyanotic population, cyanotic patients demonstrate inferior myocardial protection even after cardioplegia, with comparatively shorter ischemic intervals. ${ }^{4}$ Despite several metabolic adaptive mechanisms in cyanotic children, hypoxia reduces the antioxidant reserve capacity, thus rendering them more susceptible to the oxidative stress of ischemia (ie, aortic clamping) and reoxygenation (ie, reperfusion). ${ }^{5}$ Contact of blood cells with the bypass circuit surface during CPB initiates a systemic inflammatory reaction that may cause organ dysfunction after CPB, particularly in lungs, heart, and brain. ${ }^{5}$ During reperfusion of the myocardium after release of the aortic crossclamp (AOXC), reactive oxygen species (ROS) are formed. These can destroy nucleic acids, proteins, and carbohydrates as well as the lipid layer on the cell membrane. $^{6}$ This may lead to myocardial dysfunction characterized by endothelial damage, transvascular edema, and reduced compliance of the ventricles. The subsequent low cardiac output syndrome (LCOS) is a cause of perioperative morbidity and mortality after surgical successful repair of cyanotic congenital heart defects like tetralogy of Fallot (TOF)..$^{1-3,7-9}$

An increasing number of researchers during the past decade have suggested that the enzyme xanthine oxidase (XO), which is a generator of ROS, plays an important role in various forms of ischemic tissue and vascular injuries, inflammatory diseases, and chronic heart failure. ${ }^{10-12}$ Allopurinol is an inhibitor of this enzyme $e^{13,14}$ and may decrease ROS, lower markers of myocardial cellular injury, ${ }^{13,14}$ and may improve recovery of myocardial function following CPB ${ }^{13,14}$ In a previous study ${ }^{15}$ involving adult patients undergoing surgery for valvular heart diseases, we demonstrated better postoperative outcomes after preoperative administration of allopurinol. Encouraged by the results of that study, we investigated the effects of preoperative administration of allopurinol on postoperative outcomes following intracardiac repair of TOF.

\section{MATERIALS AND METHODS}

Fifty patients (aged 1-14 years) undergoing intracardiac repair for TOF by a single surgeon (ST) at the All India Institute of Medical Sciences, New Delhi, India, between February 2015 and August 2015 were included in this double-blind, prospective randomized study. Informed consent was obtained from the parents or guardians of all patients, the institute ethics committee approved the study protocol (IEC/NP-227/2-13 dated November 9, 2013) and the trial was registered with the clinical trials registry of India (CTRI/2017/03/013692).

Exclusion criteria were TOF with atrioventricular septal defect, absent pulmonary valve, moderate-to-severe ventricular dysfunction, associated anomalous pulmonary venous connections, and emergency surgery.

\section{Sample Size and Randomization}

In our experience, on an average, we expect an inotropic score of $18 \pm 7$ with the placebo in the immediate postoperative period. Allopurinol administration is expected to reduce this score by about 6 (18 \pm 7 vs $12 \pm 6) .{ }^{15}$ To detect this difference to be statistically significant, in a 2-sided test with $\alpha=5 \%$ and power of $80 \%$, we required a minimum of 22 subjects in either group. Accordingly, a sample size of 50 with 25 patients in each group was randomized in 2 arms. The randomization list was generated using nQuery advisor version 7.0 (Statistical Solutions Ltd, Boston, Mass). This randomization sequence was transferred to sealed envelopes that were opened just before administration of the drug.

\section{Allopurinol Administration}

Both the drug and the placebo were administered orally by nursing staff members. The placebo was prepared in the hospital pharmacy and consisted of sugar tablets identical to the drug tablets. The first dose of the drug was administered orally 12 hours before surgery $(10 \mathrm{mg} / \mathrm{kg} /$ dose); the second dose was administered orally with a sip of water in the morning, just before shifting to the operating room; and 3 subsequent doses were administered 12, 24, and 36 hours after surgery through a nasogastric tube. All members of the surgical team, the anesthesiologist, laboratory staff, and the statistician were blinded to the type of drug used.

\section{Anesthesia Technique}

Anesthesia technique was standardized for all patients. All patients received cefotaxime $30 \mathrm{mg} / \mathrm{kg}$ as antibiotic prophylaxis at the time of placement of the intravenous line. Intravenous induction with $2 \mathrm{mg} / \mathrm{kg}$ ketamine, $2 \mu \mathrm{g} / \mathrm{kg}$ fentanyl, and $1 \mathrm{mg} / \mathrm{kg}$ rocuronium was used. Sevoflurane with air and oxygen was used for maintenance to maintain minimum alveolar concentration of $0.8: 1$. Doses of $0.1 \mathrm{mg} / \mathrm{kg}$ midazolam, $0.1 \mu \mathrm{g} / \mathrm{kg}$ fentanyl, and $0.1 \mathrm{mg} / \mathrm{kg}$ vecuronium were used intermittently. A 5-mL sample of blood was obtained after insertion of invasive lines for estimation of baseline levels of biochemical markers.

\section{Surgical Technique and Postoperative Care}

Before making the skin incision, venous blood samples were taken in a plain vial. Cardiac output was measured using noninvasive impedance cardiometry method with an Icon monitor (Icon Osypka Medical GmBH, Berlin, Germany). ${ }^{16}$ Standard median sternotomy was performed and standard hypothermic $\left(28^{\circ} \mathrm{C}-32^{\circ} \mathrm{C}\right) \quad \mathrm{CPB}$ was established using aortobicaval cannulation with the aid a nonpulsatile roller pump, membrane oxygenator, and standard extracorporeal circuits. The CPB circuit was primed with fresh blood per standard criteria with or without Plasmalyte-A (Baxter International, Deerfield, Ill) as needed. Heparin, mannitol, and sodium bicarbonate were added to the circuit as required. CPB was carried out at flow rates of 150 to $200 \mathrm{~mL} / \mathrm{kg} / \mathrm{min}$ with cooling at the rate of $1^{\circ} \mathrm{C}$ per minute and rewarming at the rate of $1^{\circ} \mathrm{C}$ every 3 minutes. Antegrade del Nido cardioplegia was administered in a single dose of $20 \mathrm{~mL} / \mathrm{kg}$. Topical cooling with cold saline solution was used. A hemofilter was always incorporated into the CPB circuit and conventional 
ultrafiltration was carried out in all patients. Modified ultrafiltration was not carried out in any patient. Standard techniques for TOF repair were employed in all patients. The vascular septal defect was closed through the right atrium and depending on need, a transannular patch was placed after resection of hypertrophied muscle bundles in the right ventricular outflow. The degree of resection and transannular patching was similar in both groups.

Dobutamine $(5 \mu \mathrm{g} / \mathrm{kg} / \mathrm{min})$ and sodium nitroprusside $(0.5 \mu \mathrm{g} / \mathrm{kg} / \mathrm{min})$ were started electively in all patients before terminating CPB. Hypotension was managed by optimizing fluid status and $/$ or noradrenaline $(0.05 \mu \mathrm{g} / \mathrm{kg} / \mathrm{min})$. Adrenaline infusion was started depending on the cardiac contractility. At the completion of the repair, right ventricular pressure/left ventricular pressure was obtained and a value up to 0.6 was accepted. Transesophageal echocardiography was performed in all patients to confirm adequacy of repair and assess ventricular function.

\section{Cardiac Output Measurements}

Cardiac output was measured by noninvasive electrical cardiometry using the Icon monitor before starting the surgery, immediately after weaning off $\mathrm{CPB}$, and 6 hours after arrival in the intensive care unit (ICU). Cardiac index values using this method have previously been found to correlate with those obtained using standard invasive cardiac monitoring in adults. ${ }^{16}$

\section{Biochemical Analysis}

Three samples for each biochemical parameter were obtained. The first sample was obtained before initiation of $\mathrm{CPB}$, the second sample was obtained immediately after releasing the AOXC and the final sample was obtained 2 hours after termination of $\mathrm{CPB}$. All blood samples were centrifuged and the separated serum was stored at $-80^{\circ} \mathrm{C}$ for preservation of the enzyme system. Whole blood levels of malondialdehyde (MDA), an important indicator of lipid peroxidation, were measured based on the spectrophotometric measurement of the color produced during the reaction of thiobarbituric acid with MDA. The concentration of thiobarbituric acid reactive substances was calculated by the absorbance coefficient of the MDA-thiobarbituric acid complex. ${ }^{17}$ Superoxide dismutase (SOD) levels measurement was based on the inhibition of nitro blue tetrazolium reduction by the $\mathrm{XO}$ system as a superoxide generator. ${ }^{18}$ Interleukin (IL) 6 and IL- $\beta$ and troponin-I measurements were made using the enzyme-linked immunosorbent assay method.

\section{Postoperative Care}

After surgery, all patients were transferred to the ICU and received standard ICU care by the same team that was blinded to the type of drug administered. No steroids or nonsteroidal anti-inflammatory drugs were given throughout the investigation period. Opioids were administered for postoperative analgesia. Inotropic support was optimized as needed, and the dose and duration of the inotropic support was recorded. Postoperatively, clinical parameters assessed were cardiac rhythm, requirement of inotropes, duration of mechanical ventilation, cardiac index, and occurrence of LCOS. The latter was defined per standard criteria that include subjective determination of reduced peripheral perfusion with diminishing urine output and increasing lactate levels with acidosis, and hemodynamic instability despite optimal inotropic support.

All patients had detailed serial transthoracic echocardiograms before being discharged from the ICU for assessment of adequacy of repair and ventricular function. The inotropic requirement was assessed in terms of inotropic score calculated by the following formula ${ }^{19}$ :

inotropic score $=$ dose in $\mu \mathrm{g} / \mathrm{kg} / \mathrm{min}$ of $($ dopamine + dobutamine $) \times$

$$
1+\text { milrinone } \times 30+(\text { epinephrine }+ \text { norepinephrine }) \times 100
$$

\section{Statistical Analysis}

Statistical analysis was performed using Stata 14.0 software (StataCorp LP, College Station, Tex). Values are presented as mean \pm standard deviation with median and interquartile rage (IQR) for quantitative variables and $\mathrm{n}(\%)$ for qualitative variables. The allopurinol and placebo groups were compared with respect to demographic and hemodynamic variables by Student $t$ test for continuous variables and $\chi^{2}$ test for categorical variables. For those variables suspected to be nonnormal, the nonparametric Wilcoxon rank-sum test was used. Clinical outcomes, including LCOS, mechanical ventilation $>24$ hours, and death were compared between techniques by Fisher exact test.

\section{RESULTS}

Out of 25 patients who were administered allopurinol, there was 1 early death. This patient had an uneventful intraoperative course and was extubated in the postoperative period. He had pulmonary hemorrhage followed by excessive mediastinal drainage and was suspected to have cardiac tamponade. At emergency re-exploration, he experienced cardiac arrest and required cardiopulmonary resuscitation and was placed on extracorporeal membrane oxygenation support. However, he could not be weaned off extracorporeal membrane oxygenation and died after 3 days.

As detailed in Table 1, there were no differences in the demographic, preoperative, and intraoperative characteristics of patients in the groups.

\section{Postoperative Characteristics}

Postoperative characteristics are tabulated in Table 2 and only the salient points are described here.

In both groups, intraoperative tranesophageal echocardiography and postoperative echocardiography before discharge from the hospital revealed no residual surgical defects and normal biventricular function. The inotropic scores were significantly lower in the allopurinol compared with the placebo group (mean, $11.04 \pm 5.7$ vs $17.5 \pm 7.83 ; P=.02$ ). The duration of mechanical ventilation was also significantly lower in the allopurinol compared with the placebo group (mean, $7.08 \pm 1.9$ hours and median, 6.5 hours vs mean, $9.28 \pm 3.98$ hours and median, 8 hours; $P=.01$ ). We followed a policy of early extubation unless signs of frank LCOS were present.

There were 11 patients in the placebo group who had significant pleural effusions ( 8 for $<2$ days and 3 for $>2$ days). In the allopurinol group, only 5 patients had pleural effusion ( 1 for $>2$ days) $(P=.13)$.

Of the 25 patients in placebo group, 8 had arrhythmias out of which 7 patients had junction ectopic tachycardia, and 1 had sinus tachycardia. In the allopurinol group, 5 patients had arrhythmia of whom 3 had junction ectopic tachycardia, 1 had sinus tachycardia, and 1 had bradycardia requiring temporary pacing. No patient had deranged liver function tests or complete heart block.

No patient in either group demonstrated manifest features of LCOS. However, there were no differences in the cardiac output from the baseline preoperative values and those obtained immediately after termination of CPB. Subsequently, the readings obtained 6 hours after 
TABLE 1. Demographic, preoperative, and intraoperative characteristics of patients in both groups

\begin{tabular}{|c|c|c|c|}
\hline Parameter & $\begin{array}{l}\text { Placebo group } \\
\quad(\mathbf{n}=\mathbf{2 5})\end{array}$ & $\begin{array}{l}\text { Allopurinol group } \\
\qquad(\mathbf{n}=\mathbf{2 5})\end{array}$ & $P$ value \\
\hline \multicolumn{4}{|l|}{ Age $(y)$} \\
\hline Mean \pm standard deviation & $4.8 \pm 4.2$ & $3.6 \pm 2.2$ & .21 \\
\hline Median (interquartile range) & $3(2-7)$ & $3(2-5)$ & \\
\hline \multicolumn{4}{|l|}{ Weight (kg) } \\
\hline Mean \pm standard deviation & $17.2 \pm 10.1$ & $13.8 \pm 4.9$ & .14 \\
\hline Median (interquartile range) & $10.0(9-24)$ & $12(9-18)$ & \\
\hline $\operatorname{Sex}(M: F)$ & $17: 8$ & $19: 6$ & .53 \\
\hline \multicolumn{4}{|c|}{ Preoperative cardiac index $\left(\mathrm{L} / \mathrm{min} / \mathrm{m}^{2}\right)$} \\
\hline Mean \pm standard deviation & $3.45 \pm 0.49$ & $3.65 \pm 0.48$ & .86 \\
\hline Median (interquartile range) & $3.4(3.1-3.5)$ & $3.8(3.2-4.0)$ & \\
\hline MAPCA (\%) & $10 / 25(40)$ & $9 / 25(36)$ & .77 \\
\hline Transannular patch & $10 / 25(40)$ & $10 / 25(40)$ & 1.0 \\
\hline \multicolumn{4}{|l|}{ CPB time (min) } \\
\hline Mean \pm standard deviation & $73.64 \pm 23.4$ & $66.4 \pm 19.2$ & .27 \\
\hline Median (interquartile range) & $65(56-90)$ & $62(51-79)$ & \\
\hline \multicolumn{4}{|l|}{ AOCX time (min) } \\
\hline Mean \pm standard deviation & $48.64 \pm 14.6$ & $46.08 \pm 12.9$ & .16 \\
\hline Median (interquartile range) & $45(39-61)$ & $42(37-48)$ & \\
\hline \multicolumn{4}{|l|}{ Time to cardiac activity $(\mathrm{s})^{*}$} \\
\hline Mean \pm standard deviation & $48.0 \pm 23.8$ & $44.4 \pm 7.76$ & .30 \\
\hline Median (interquartile range) & $48(23.5-67)$ & $41.5(32-59)$ & \\
\hline
\end{tabular}

$\overline{M A P C A}$, Major aortopulmonary collateral arteries; $C P B$, cardiopulmonary bypass; $A O C X$, aortic crossclamp. *Time to resumption of cardiac activity following release of aortic crossclamp.

arrival in the ICU demonstrated higher median cardiac indices in the allopurinol group $4.0 \mathrm{~L} / \mathrm{min} / \mathrm{m}^{2}$ (IQR, 3.6- $4.2 \mathrm{~L} / \mathrm{min} / \mathrm{m}^{2}$ ) compared with $3.2 \mathrm{~L} / \mathrm{min} / \mathrm{m}^{2}$ (IQR, 2.9-3.6 $\left.\mathrm{L} / \mathrm{min} / \mathrm{m}^{2}\right)$ in the placebo group $(P=.009)$. In patients receiving allopurinol, the mean duration of ICU $(P=.001)$ and hospital stay $(P=.01)$ were significantly less. To assess the effects of baseline characteristics on the postoperative clinical outcomes following administration of allopurinol, adjustments were made for the

TABLE 2. Postoperative parameters of the 2 groups

\begin{tabular}{lccc}
\hline \multicolumn{1}{c}{ Parameter } & $\begin{array}{c}\text { Placebo group } \\
(\mathbf{n}=\mathbf{2 5})\end{array}$ & $\begin{array}{c}\text { Allopurinol } \\
\text { group } \\
(\mathbf{n}=\mathbf{2 5})\end{array}$ & $\begin{array}{c}\boldsymbol{P} \\
\text { value }\end{array}$ \\
\hline Mechanical ventilation (h) & $8(7-10)$ & $6.5(6-8)$ & .01 \\
\hline ICU stay (h) & $48(36-60)$ & $31.5(24.5-42)$ & .001 \\
\hline Hospital stay (d) & $6(6-8)$ & $5(5-5)$ & .01 \\
Arrhythmias (\%) & $8 / 25(32)$ & $5 / 25(20)$ & .33 \\
Pleural effusion & $11 / 25(44)$ & $5 / 25(20)$ & .13 \\
Inotropic score & $15(15-20)$ & $10(7.5-12.5)$ & .02 \\
Cardiac index (L/min/m²) & & & \\
$\quad$ Preoperative & $3.4(3.1-3.5)$ & $3.8(3.2-4.0)$ & .16 \\
$\quad$ Post-CPB & $3.2(2.9-3.6)$ & $3.6(3.2-3.5)$ & .07 \\
$\quad$ After 6 h in ICU & $3.2(2.9-3.6)$ & $4.0(3.6-4.2)$ & .009 \\
\hline
\end{tabular}

Values are presented as median (interquartile range) or $\mathrm{n} / \mathrm{n}(\%)$. ICU, Intensive care unit; $C P B$, cardiopulmonary bypass. baseline variables. It was observed that the differences in both the groups remained significant. For example, the

TABLE 3. Postoperative biochemical markers

\begin{tabular}{lccc}
\hline \multicolumn{1}{c}{ Parameter } & $\begin{array}{c}\text { Placebo group } \\
(\mathbf{n}=\mathbf{2 5})\end{array}$ & $\begin{array}{c}\text { Allopurinol } \\
\text { group } \\
(\mathbf{n = 2 5})\end{array}$ & $\boldsymbol{P}$ value \\
\hline SOD before CPB & $2.82(1.98-3.45)$ & $3.96(3.07-5.78)$ & .012 \\
\hline SOD after AOCX & $2.1(1.6-3.1)$ & $4.89(2.98-6.71)$ & $<.001$ \\
\hline SOD after CPB & $1.83(1.68-2.63)$ & $3.03(2.02-4.34)$ & .003 \\
\hline IL-6 before CPB & $2(1.1-11)$ & $0(0-2.3)$ & .028 \\
\hline IL-6 after AOCX & $28(12-41)$ & $4.86(0-18)$ & $<.001$ \\
\hline IL-6 after CPB & $112(69-130)$ & $32(18-73)$ & $<.001$ \\
\hline IL- $\beta$ before CPB & $0(0-0)$ & $0(0-0)$ & 1 \\
\hline IL- $\beta$ after AOCX & $0(0-15.6)$ & $0(0-0)$ & $<.001$ \\
\hline IL- $\beta$ after CPB & $9(0-13)$ & $0(0-0)$ & .007 \\
\hline Trop-I before CPB & $0(0-1.2)$ & $0(0-0)$ & .21 \\
\hline Trop-I after AOCX & $10.2(7-13)$ & $11(8-12)$ & .75 \\
\hline Tropo-I after CPB & $26(20-40)$ & $20(18-24)$ & .028 \\
\hline MDA before CPB & $3(2-5)$ & $4(3-5)$ & .504 \\
\hline MDA after AOCX & $6(5-8)$ & $8(6-11)$ & .126 \\
\hline MDA after CPB & $11(10-12)$ & $8(7-10)$ & $<.001$ \\
\hline
\end{tabular}

Values are presented as median (interquartile range). Post-CPB samples were obtained $2 \mathrm{~h}$ after terminating CPB. $S O D$, Superoxide dismutase $(\mathrm{U} / \mathrm{mL}) ; C P B$, cardiopulmonary bypass; $A O C X$, aortic crossclamp; $I L$, interleukin (pg/mL); Trop-I, troponin-I (ng/mL); $M D A$, malondialdehyde (pg/mL). 


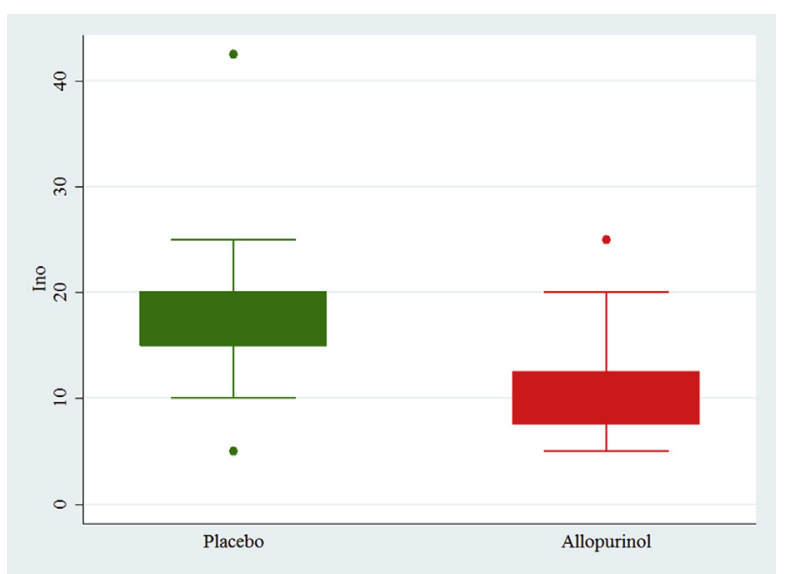

FIGURE 1. Comparison of inotropic (INO) scores between the allopurinol and placebo groups.

mean difference in ICU stay was 21.7 hours $(P<.001)$ between the 2 groups $(33.71 \pm 12$ hours in allopurinol vs $55.5 \pm 28.9$ hours in the placebo group), which still turned out to be 21.3 hours $(P=.002)$ after adjusting for age of the patient.

\section{Biochemical Analysis}

Table 3 and Figures 1 through 5 show the results of biochemical assay. The mean preoperative levels of SOD were $4.5 \pm 2.08$ versus $2.87 \pm 1.21 \mathrm{U} / \mathrm{mL}$ in the allopurinol and placebo groups, respectively; $P=.001$ ). This is consistent with the fact that allopurinol has an antioxidant effect. The levels of SOD at subsequent time points were also higher in the allopurinol group. On average, SOD levels were higher by $1.7 \mathrm{U} / \mathrm{mL}$ before CPB $(P=.012), 3 \mathrm{U} / \mathrm{mL}$ after release of AOXC $(P<.001)$ and $1.26 \mathrm{U} / \mathrm{mL} 2$ hours after termination of CPB $(P=.003)$ in the allopurinol group.

The mean preoperative levels of IL- 6 were on average lower by $3.2 \mathrm{pg} / \mathrm{mL}$ before CPB, $21.4 \mathrm{pg} / \mathrm{mL}$ after release

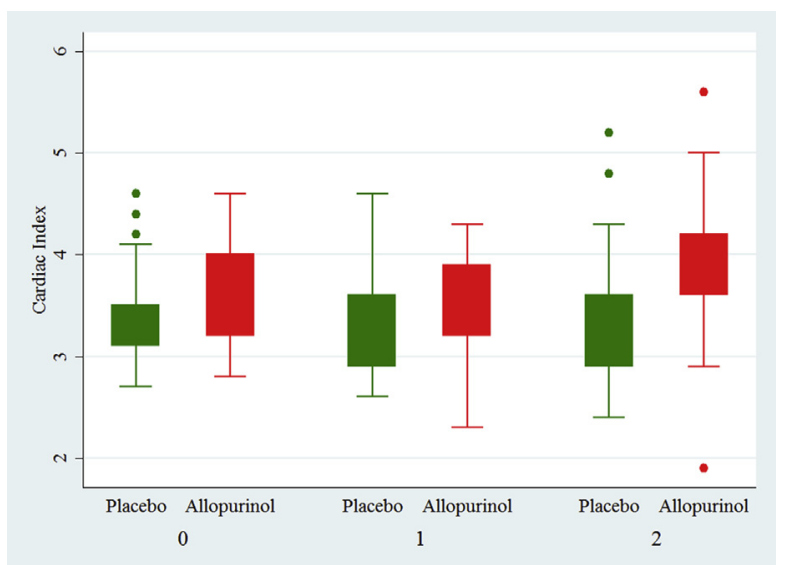

FIGURE 2. Comparison of cardiac index $\left(\mathrm{L} / \mathrm{min} / \mathrm{m}^{2}\right)$ between the allopurinol and placebo groups $(1=$ preoperative, $2=$ after cardiopulmonary bypass, and $3=$ after 6 hours in the intensive care unit).

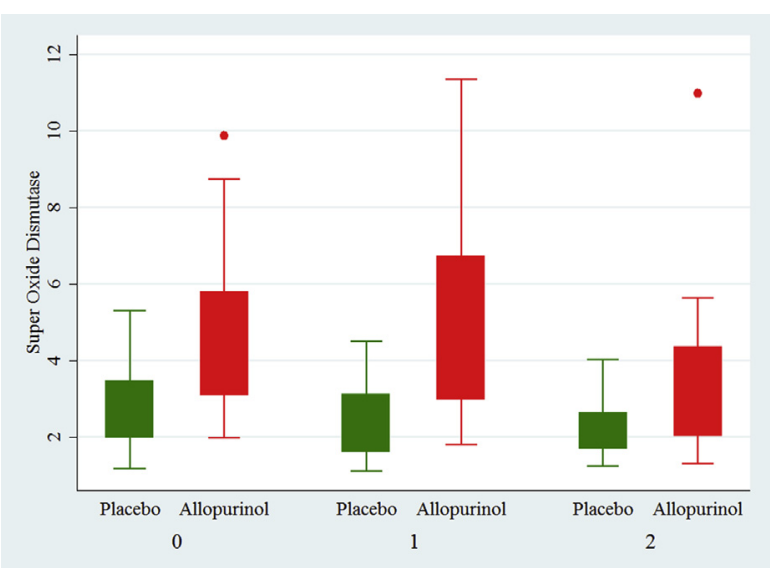

FIGURE 3. Comparison of superoxide dismutase levels $(\mathrm{U} / \mathrm{mL})$ between the allopurinol and placebo groups $(1=$ before cardiopulmonary bypass, $2=$ after release of aortic crossclamp, and $3=$ after cardiopulmonary bypass).

of AOXC, and $55.9 \mathrm{pg} / \mathrm{mL}$ in the allopurinol group. The levels of IL- $\beta$ pre-CPB were similar in both groups. However, these levels were higher post-AOXC release and 2 hours after termination of CPB by an average of $9.45 \mathrm{pg} / \mathrm{mL}(P<.001)$ and $6.28 \mathrm{pg} / \mathrm{mL}(P=.007)$, respectively.

Troponin-I levels, which are an indicator of myocardial injury, were no different between the 2 groups until the sample obtained at 2 hours after termination of CPB. At this time point, the average levels were lower by $6.84 \mathrm{ng} / \mathrm{mL}$ in patients receiving allopurinol $(P=.028)$. Similarly, the baseline levels of MDA were on average higher in the placebo group by $0.2 \mathrm{pg} / \mathrm{mL}(P=.504)$. These levels were subsequently less by $1.04 \mathrm{pg} / \mathrm{mL}(P=.126)$ and $2.64 \mathrm{pg} / \mathrm{mL}(P<.001)$ in patients receiving allopurinol (Figures 6 and 7).

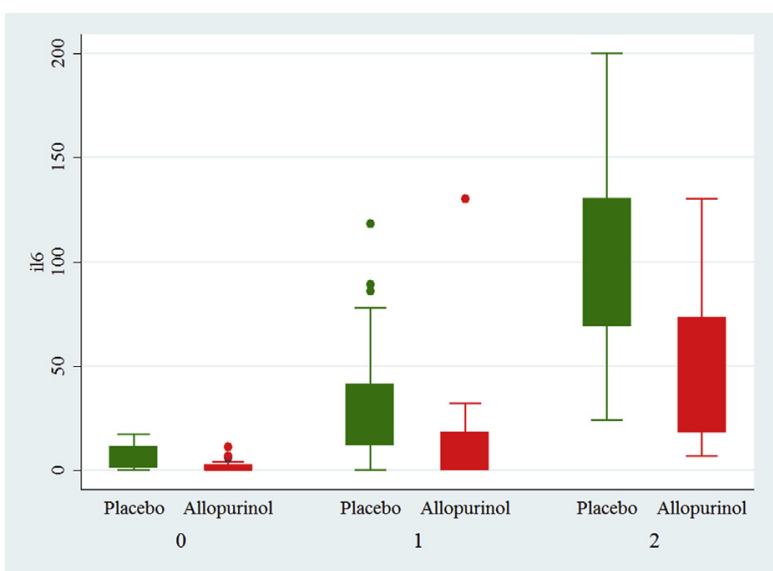

FIGURE 4. Comparison of interleukin 6 (ilo) levels (pg/mL) between the allopurinol and placebo groups $(1=$ before cardiopulmonary bypass, $2=$ after release of aortic crossclamp, and $3=$ after cardiopulmonary bypass). 


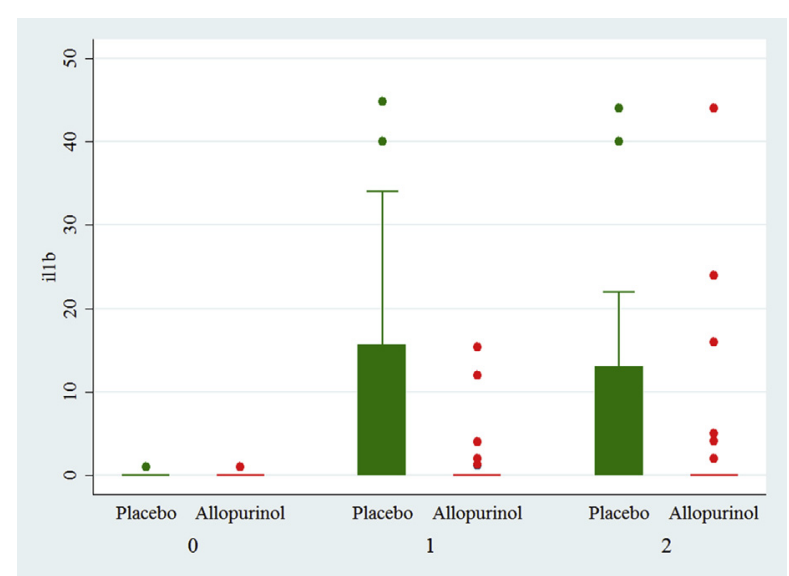

FIGURE 5. Comparison of interleukin $\beta$ (illb) levels (pg/mL) between the allopurinol and placebo groups $(1=$ before cardiopulmonary bypass, $2=$ after release of aortic crossclamp, and $3=$ after cardiopulmonary bypass).

\section{DISCUSSION}

Based on our own publication on allopurinol in patients with valvular heart diseases, we tried to investigate the effects of administration of allopurinol on postoperative outcomes in patients with TOF. Clancy and colleagues ${ }^{20}$ investigated the effects of administration of allopurinol in patients with complex congenital heart diseases. In this single-center, randomized, placebo-controlled, blinded trial that studied the effects of administration of allopurinol in 350 infants undergoing repair of congenital heart defects under deep hypothermia and circulatory arrest or heart surgery using deep hypothermic circulatory arrest. Allopurinol provided significant neurocardiac protection in higher-risk infants with a diagnosis of hypoplastic left heart syndrome but not in infants with other diagnoses. No adverse effects were noted as a result of allopurinol administration in that study and in ours. Our study did not

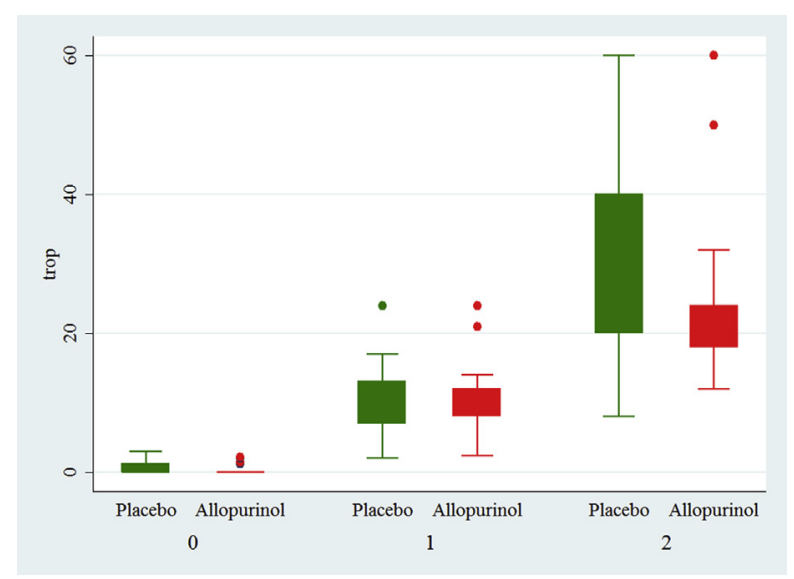

FIGURE 6. Comparison of troponin-I (trop) levels (ng/mL) between the allopurinol and placebo groups $(1=$ before cardiopulmonary bypass, $2=$ after release of aortic crossclamp, and $3=$ after cardiopulmonary bypass). examine the effects of allopurinol administration in patients with complex diagnoses because our study was limited only to patients undergoing intracardiac repair of TOF because that is the most common subset in our clinical practice. Restricting this study to patients undergoing TOF repair also ensured a uniform patient population in whom the degree of infundibular resection and the need for transannular patches was similar.

The results of our study demonstrate that patients who were administered allopurinol fared better than those who were offered placebo drug in terms of the need for inotropes and shorter ICU and hospital stays.

Randomized studies in adults undergoing coronary artery bypass grafting have demonstrated reduced early mortality and have shown similar benefits ${ }^{21,22}$ along with reduced markers of ischemia and free-radical generation. In our study, we were able to demonstrate a significant reduction in levels of IL-6, troponin-I, and MDA. Cardiac indices were similar in both groups after termination of CPB and improved only 6 hours following surgery in the allopurinol group; however, although echocardiography did not reveal any differences in the functional cardiac parameters in both the groups. The duration of mechanical ventilation was also lower in patients receiving allopurinol. These findings probably signify that the improvement in clinical state and favorable cardiac markers following allopurinol administration may be related to its systemic anti-inflammatory characteristics rather than an improvement in myocardial function.

Compared with normal hearts, ATP production has been shown to be diminished in chronically hypoxic hearts due to reduced oxidation of fatty acids and carbohydrates. ${ }^{8}$ This may lead to cell injury and cell death. During heart surgery, exposure of the blood to the extracorporeal circuit activates the complement system and the intrinsic coagulation cascade that ultimately induce the synthesis of proinflammatory cytokines that are intercellular messengers. $^{23,24}$ These changes ultimately lead to generation of superoxide radicals due to accumulation of $\mathrm{XO}$ and other ROS-mediated ischemia-reperfusion injury. ${ }^{25-28}$ Allopurinol is known to be an inhibitor of XO, and this effect can be used for clinical benefits. Besides these effects, allopurinol has been shown to improve myocardial oxygen consumption in heart failure ${ }^{29}$ and also prolong the time to ischemia during exercise in adults with chronic stable angina. ${ }^{30}$

In our study, SOD levels were higher in patients receiving allopurinol. This further reinforces our findings of a significant antioxidant effect of allopurinol. A study from Indonesia also demonstrated increased SOD levels after allopurinol administration in patients with $\mathrm{TOF}^{31}$ For many years, MDA has been widely used as a convenient biomarker for lipid peroxidation ${ }^{18}$ of omega- 3 and omega- 6 fatty acids because of its facile reaction with thiobarbituric acid. ${ }^{17}$ 


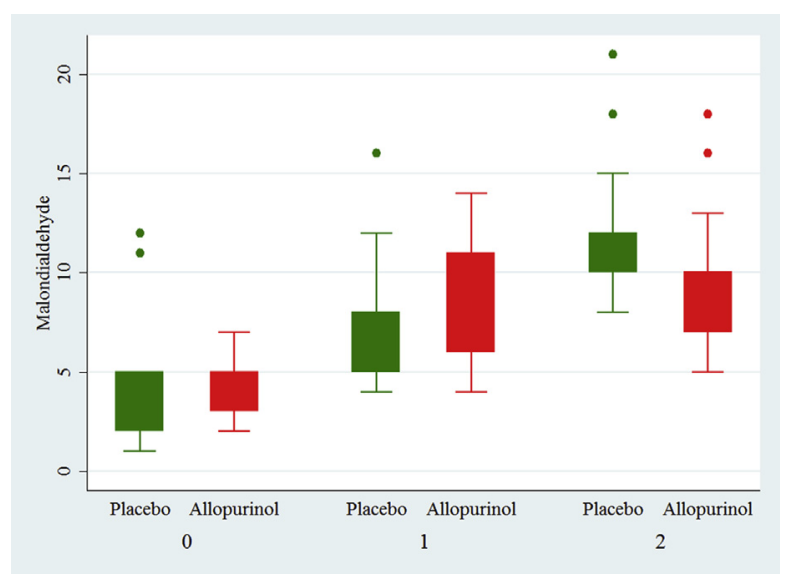

FIGURE 7. Comparison of plasma malondialdehyde levels $(\mathrm{pg} / \mathrm{mL})$ between the allopurinol and placebo groups $(1=$ before cardiopulmonary bypass, $2=$ after release of aortic crossclamp, and $3=$ after cardiopulmonary bypass).

Following CPB, levels of MDA are expected to increase. In our study, we did not observe any significant differences in the first 2 samples, but the levels of MDA were significantly lower 2 hours after termination of CPB in the allopurinol group, signifying that lipid peroxidation with raised MDA levels continue to occur even after termination of CPB and the levels reduce only later. Allopurinol is thus helpful even after termination of ischemia and CPB. However, no adverse events or drug interactions were noted in our study. The former may include hypersensitivity reactions, toxic epidermal necrolysis, Stevens Johnson syndrome, hypotension, gastrointestinal disturbances, dark urine, and jaundice. Important drug interactions include those with chemotherapeutic agents; antibiotics like ampicillin, amoxicillin, and clavunalic acid; and diuretics. Caution must be exercised while using these drugs in patients receiving allopurinol. ${ }^{32}$

The drug is inexpensive and the major adverse effects listed above are rare, making it an attractive option in children with cyanotic heart disease who experience chronic hypoxia and have a lower antioxidant reserve. $^{12}$

\section{Study Limitations}

The sample size in this study was small. The duration of allopurinol therapy was empirical and we did not obtain preadministration biochemical parameters. The age of patients in this study was considerably older than those encountered at most centers worldwide. In addition, the method adopted for measurement of cardiac index is not yet standardized in children. However, a previous study from our institute has shown cardiac indices calculated by this method to correlate well with standard invasive methods in aduts. ${ }^{16}$ Ideally, a large patient population across all ages with simple and complex diagnoses undergoing more frequent biochemical estimations before administration, during and after operation, and continuous invasive cardiac output monitoring is needed to better elucidate the results.

\section{CONCLUSIONS}

Allopurinol administration in patients undergoing intracardiac repair of TOF is associated with reduced inotropic scores, duration of mechanical ventilation, and ICU and hospital stays, and favorable biochemical markers of inflammation. These effects translate into improved early outcomes. Further studies in multiple setups are needed for confirmation of these findings and to determine the timing, dosage, and duration of therapy before recommending it as a routine practice.

\section{Webcast}

You can watch a Webcast of this AATS meeting presentation by going to: http://webcast.aats.org/2016/ Video/Monday/05-16-16_Ballroom_III_1615_Talwar-800. mp4.

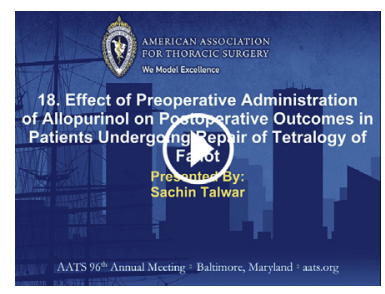

\section{Conflict of Interest Statement}

Authors have nothing to disclose with regard to commercial support.

\section{References}

1. Holmes JH IV, Connolly NC, Paull DL, Hill ME, Guyton SW, Ziegler SF, et al. Magnitude of the inflammatory response to cardiopulmonary bypass and its relation to adverse clinical outcomes. Inflamm Res. 2002;51: 579-86.

2. Christen S, Finckh B, Lykkesfeldt J, Gessler P, Frese-Schaper M, Nielsen Schmidt ER, et al. Oxidative stress precedes peak systemic inflammatory response in pediatric patients undergoing cardiopulmonary bypass operation. Free Radic Biol Med. 2005;38:1323-32.

3. Del Nido PJ, Mickle DAG, Wilson GJ, Benson LN, Weisel RD, Coles JG, et al. Inadequate myocardial protection with cold cardioplegic arrest during repair of tetralogy of Fallot. J Thorac Cardiovasc Surg. 1988;95:223-9.

4. Imura H, Caputo M, Parry A, Pawade A, Angelini GD, Suleiman M Age-dependent and hypoxia-related differences in myocardial protection during pediatric open heart surgery. Circulation. 2001;103:1551-6.

5. Ihnken K, Morita K, Buckberg GD, Matheis G, Sherman MP, Allen BS, et al. Studies of hypoxemic/reoxygenation injury: without aortic clamping. II. Evidence for reoxygenation damage. J Thorac Cardiovasc Surg. 1995;110:1171-81.

6. Turer AT, Hill JA. Pathogenesis of myocardial ischemia-reperfusion injury and rationale for therapy. Am J Cardiol. 2010;106:360-8.

7. Del Nido PJ, Mickle D, Wilson GJ, Benson LN, Coles JG, Trusler GA, et al. Evidence of myocardial free radical injury during elective repair of tetralogy of Fallot. Circulation. 1987;76(Suppl V):V174-9. 
8. Silverman NA, Kohler J, Levitsky S, Pavel DG, Fang RB, Feinberg H Chronic hypoxemia depresses global ventricular function and predisposes to the depletion of high-energy phosphates during cardioplegic arrest: implications for surgical repair of cyanotic congenital heart defects. Ann Thorac Surg. 1984; 37:304-8.

9. Paparella D, Yau TM, Young E. Cardiopulmonary bypass induced inflammation: pathophysiology and treatment. An update. Eur J Cardiothorac Surg. 2002;21: 232-44.

10. Harrison R. Physiological roles of xanthine oxidoreductase. Drug Metab Rev. 2004;36:363-75.

11. Berry CE, Hare JM. Xanthine oxidoreductase and cardiovascular disease: molecular mechanisms and pathophysiological implications. J Physiol (Lond). 2004:555:589-606.

12. Giordano FJ. Oxygen, oxidative stress, hypoxia, and heart failure. J Clin Invest. 2005;115:500-8

13. England MD, Cavarocchi NC, O’Brien JF, Solis E, Pluth JR, Orszulak TA, et al. Influence of antioxidants (mannitol and allopurinol) on oxygen free radical generation during and after cardiopulmonary bypass. Circulation. 1986;74: III134-I137.

14. Zoran P, Juraj F, Ivana D, Reik H, Dusan N, Mihailo V. Effects of allopurinol on oxygen stress status during open heart surgery. Int J Cardiol. 1994:44:123-9.

15. Talwar S, Sandeep JA, Choudhary SK, Velayoudham D, Lakshmy R, Kasthuri JM, et al. Effect of preoperative administration of allopurinol in patients undergoing surgery for valvular heart diseases. Eur J Cardiothorac Surg. 2010; 38:86-90.

16. Malik V, Subramanian A, Chauhan S, Hote M. Correlation of electric cardiometry and continuous thermodilution cardiac output monitoring systems. World J Cardiovasc Surg. 2014;4:101-8.

17. Zhao L, Peng D-Q, Zhang J, Song JQ, Teng X, Yu YR, et al. Extracellular signal-regulated kinase $1 / 2$ activation is involved in intermedin1-53 attenuating myocardial oxidative stress injury induced by ischemia/reperfusion. Peptides. 2012;33:329-35.

18. MacGowan SW, Regan MC, Malone C, Sharkey O, Young L, Gorey TF Superoxide radical and xanthine oxidoreductase activity in the human heart during cardiac operations. Ann Thorac Surg. 1995;60:1289-93.

19. Wernovsky G, Wypij D, Jonas RA, Mayer JE Jr, Hanley FL, Hickey PR, et al. Postoperative course and hemodynamic profile after the arterial switch operation in neonates and infants. A comparison of low-flow cardiopulmonary bypass and circulatory arrest. Circulation. 1995;92:2226-35.

20. Clancy RR, McGaurn SA, Goin JE, Hirtz DG, Norwood WI, Gaynor JW, et al. Allopurinol neurocardiac protection trial in infants undergoing heart surgery using deep hypothermic circulatory arrest. Pediatrics. 2001;108: $61-70$.

21. Johnson WD, Kayser KL, Brenowitz JB, Saedi SF. A randomized controlled trial of allopurinol in coronary bypass surgery. Am Heart J. $1991 ; 121: 20-4$

22. Weimert NA, Tanke WF, Sims JJ. Allopurinol as a cardio protectant during coronary artery bypass graft surgery. Ann Pharmacother. 2003;37: 1708-11.

23. Solaini G, Harris DA. Biochemical dysfunction in heart mitochondria exposed to ischaemia and reperfusion. Biochem J. 2005;390:377-94.

24. Takabayashi T, Vannier E, Clark BD, Margolis NH, Dinarello CA, Burke JF, et al. A new biologic role for $\mathrm{C} 3 \mathrm{a}$ and $\mathrm{C} 3 \mathrm{a}$ desArg: regulation of TNF- $\alpha$ and $\mathrm{IL}-1 \beta$ synthesis. J Immunol. 1996;156:3455-60.

25. Matsushima K, Taguchi M, Kovacs EJ, Young HA, Oppenheim JJ. Intracellular localization of human monocyte associated interleukin 1 (IL 1) activity and release of biologically active IL 1 from monocytes by trypsin and plasmin. J Immunol. 1986;136:2883-91.

26. Fischer WH, Jagels MA, Hugli TE. Regulation of IL-6 synthesis in human peripheral blood mononuclear cells by $\mathrm{C} 3 \mathrm{a}$ and $\mathrm{C} 3 \mathrm{a}$ (desArg). J Immunol. 1999;162:453-9.

27. Hennein HA, Ebba H, Rodriguez JL, Merrick SH, Keith FM, Bronstein MH, et al. Relationship of the proinflammatory cytokines to myocardial ischemia and dysfunction after uncomplicated coronary revascularization. $J$ Thorac Cardiovasc Surg. 1994;108:626-35.

28. Granger DN. Role of xanthine oxidase and granulocytes in ischemia-reperfusion injury. Am J Physiol. 1988;255(6 Pt 2):H1269-75.

29. Ekelund UE, Harrison RW, Shokek O, Thakkar RN, Tunin RS, Senzaki H, et al. Intravenous allopurinol decreases myocardial oxygen consumption and increases mechanical efficiency in dogs with pacing-induced heart failure. Circ Res. 1999; $85: 437-45$.
30. Noman A, Ang DS, Ogston S, Lang CC, Struthers AD. Effect of high dose allopurinol on exercise in patients with chronic stable angina: a randomised, placebo controlled, crossover trial. Lancet. 2010;375:2161-7.

31. Rachmat FD, Rachmat J, Sastroasmoro S, Wanandi SI. Effect of allopurinol on oxidative stress and hypoxic adaptation response during surgical correction of tetralogy of Fallot. Acta Med Indones. 2013:45:94-100.

32. Oxipurinol: alloxanthine, Oxyprim, oxypurinol. Drugs R D. 2004;5:171-5.

\section{Discussion}

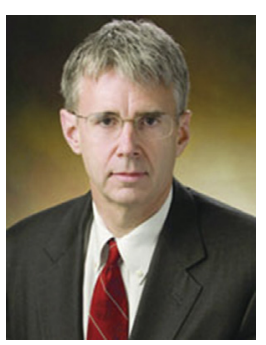

Dr J. William Gaynor (Philadephia, $\mathrm{Pa}$ ). Congratulations on an excellent presentation and a great article, and thank you for allowing me to review the manuscript.

Since the introduction of cardiopulmonary bypass 60 years ago, there has been an early recognition of the adverse effects of cardiopulmonary bypass, and particularly ischemia reperfusion and the systemic inflammatory effects on our patients, particularly the small neonates and children undergoing surgery. And there has been a search for ways to mitigate these factors. Unfortunately, very little has been shown to be consistently effective and sustain good outcomes and been proven in multiple studies.

It would be great to have a drug like allopurinol that is cheap, easily available, and very safe to use if we can show that it improves outcomes. Unfortunately, the fact that allopurinol is available, cheap, and is out of patent, it is probably not going to have a drug company looking to fund a major study.

Your study showed-both your valve study and this tetralogy of Fallot study - that there is an impact on early outcomes-not mortality, which we all hope is going to be low-but resource use, improved function, and decreased length of stay that will reduce costs and hopefully improve longer-term outcomes.

In the 1990s at Children's Hospital of Philadelphia, we did a randomized control study of allopurinol administration in neonates undergoing heart surgery. More than 300 neonates were randomized. Unfortunately, we did not see a significant effect on the primary outcome of a composite outcome of death, seizure, or coma. However, in the hypoplast subgroup, there was a significant beneficial effect of allopurinol both in decreasing cardiac events, and particularly in decreasing the seizure rate. Now, we know that occurrence of a perioperative seizure is associated with worse neurodevelopmental outcomes.

Now we have several randomized clinical trials. Some of the sample sizes are small. Some of the results may be equivocal, but that suggests there is a benefit to allopurinol.

How do we move this forward? How do we decide is this a good therapy? What do you think should be the 
mechanisms, the next steps to determine is there a beneficial effect? What's the appropriate way to use it, and then hopefully begin to disseminate those findings and introduce this into clinical care?

I congratulate you on a great presentation and a very interesting study.

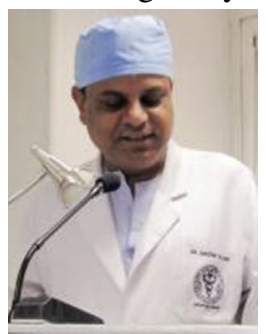
allopurinol in terms of universal outcomes, the cardiac end points were not met. Patients in the nonhypoplast group clearly did not benefit.

Among the reasons was that these patients were neonates, and if you look at the population presented in our article, now the patients who are older. They are the patients who have chronic hypoxia, and they are the patients who have more hypertrophic muscle in the right ventricular outflow tract.

Such a patient may be ideal for allopurinol because these are the patients who are likely to have more hypoxic damage to the myocardium following cardiopulmonary bypass.

To be able to address whether allopurinol is going to be beneficial or not, we need a larger number of patients. We need multi-institution trials, and probably we need to define the exact dosage. And we also need to define what should be the optimal timing of the therapy.

I think the study in neonates, particularly where one is performing a circulatory arrest, may not be a very good way to address this problem because a lot of factors come into play in circulatory arrest and neurologic outcomes and all that. A single dose of the drug may not ameliorate all those effects of cardiopulmonary bypass.

So if one were to address that issue, then probably you need to extend the timing of the preoperative therapy. First, I think the way to move forward would be to have multi-institutional trials in simple patients like tetralogy of Fallot, study all records and look at the results. And then probably extend additional therapy and look at the neonates.

Dr Gaynor. Along those lines, another population might be the Fontan population.

Dr Talwar. Exactly.

Dr Gaynor. Because we know the perioperative course after Fontan. But I think this is the type of thing where to find a therapy that is safe and hopefully effective is the holy grail that we are looking for. Particularly, if we can show that it is not, you know, many of these therapies you can measure a short-term outcome, but you don't show necessarily a benefit in longer-term outcome.

Dr Talwar. Yes, that is true.

Dr Gaynor. If you can improve neurologic outcomes as well, then you've got a very interesting therapy.

Dr Talwar. Exactly.

Dr Gaynor. Congratulations on a really nice study.

Dr Talwar. Thank you so much.

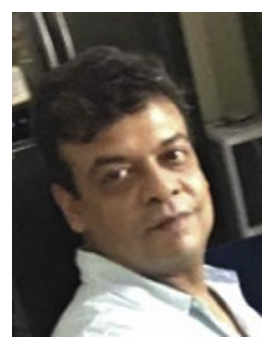

Dr Gaurav Kumar (New Delhi, India). I'm your neighbor. I operate on the same population subset. It would be difficult for most of our colleagues here to comprehend what kind of patients we really operate on in case of tetralogy.

My only comment regarding this excellent presentation is I believe that the amount of cyanosis over the long-term has a bigger influence on the free radical injury once you put a patient on bypass and follow him or her.

Dr Talwar. Yes.

Dr Kumar. So the amount of hematocrit or cyanosis: Did you include that in your study, or would you like to include it in your study when you do a larger trial? Do you think that that will make an impact on the amount of the inflammatory markers you measured during the postoperative period?

Dr Talwar. In fact, we did look at the amount of cyanosis as a predictor of outcome in both groups. But the degree of cyanosis was similar in both groups, and we did not find a difference in the patient demographic characteristics in the groups. Those data are in the article. The patient profile was similar in both groups.

Having said that, that brings us back to the same question. Should a patient who is bluer than the other patient get allopurinol in a different dose or for moderation? I do not know the answer to that question. Probably we need to have more studies to answer that question.

Dr Kumar. Same question, if you are operating a tetralogy at age 3 months, should he require allopurinol versus a patient who is undergoing operation at age 4 years?

Dr Talwar. I do not know the answer, to be very honest.

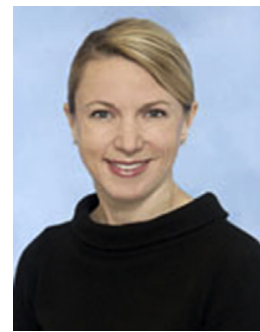

Dr Jennifer C. Hirsch-Romano (Ann Arbor, Mich). Final question. Are you expanding this to other patient populations in your center?

Dr Talwar. Pardon me?

Dr Hirsch-Romano. Are you expanding the use of allopurinol to other patient populations in your center?

Dr Talwar. I think we will be doing that in the near future, and probably we will be coming out with studies in that direction also. 